\title{
PHOTOCHEMICAL REDUCTION AND OXIDATION OF CERIUM(IV) PORPHYRIN SANDWICH COMPLEXES
}

\author{
S. RADZKI \\ Dept. of Chemistry, UMCS, PI. M. Curie-Skłodowskiej 3, 20-031 Lublin, Poland \\ and Cil. Giannotti \\ Institut de Chimie des Substances Naturelles, CNRS \\ 91198 Gif-sur-Yvette, France
}

Irradiation of cerium(IV) complex of octaethyl bisporphyrin $\mathrm{Ce}\left[\mathrm{OEP}(-2]_{2}\right.$ with visible light, in the presence of $\mathrm{CCl}_{4}$ as an electron acceptor, leads to their photooxidation and $\pi$ cation radical formation. The process was followed using electron absorption and magnetic circular dichroism spectroscopy. Electronic configuration in neutral mono- and bisporphyrin (sandwich) complexes were compared to the one of the neutral species. Photoirradiation of sandwich octaetlyy- and tetraphenyl bisporphyrins, in the presence of an electron donor (triethylamine) results in their photoreduction on different pathways. Formation of the $[\mathrm{Ce}(\mathrm{III})(\mathrm{TPP})(-2) \mathrm{TPP}(-2)]^{-}$and $[\mathrm{Ce}(\mathrm{III})(\mathrm{OEP})(-1)(\mathrm{OEP})(-2)]$ complexes was followed by absorption and electron spin resonance spectroscopy.

PACS numbers: 82.50.Fv

\section{Introduction}

The lanthanide porphyrins are the subject of considerable current interest. Potential uses as non-destructive luminescent probes in biologically active molecules [1-4] and as NMR shift reagents $[5,6]$ have been investigated. Buchler and co-workers have synthesized bis(octaethylporphyrin) sandwich complexes of all the rare-earth elements [7-14]. Analogous compounds have been prepared with tetraphenyl- and tetratolyl-porphiryn [15-17], and complexes containing different porphyrin rings [17-19] or porphyrin and phthalocyanine rings are also known $[20,21]$.

A schematic view of the ring arrangements in the sandwich octaethylporphyrin $\left(\mathrm{H}_{2} \mathrm{OEP}\right)$ and tetraphenylporphyrin $\left(\mathrm{H}_{2} \mathrm{TPP}\right)$ complexes is shown in Fig. 1. The $\mathrm{Ce}^{4+}$ cation is located between two porphyrin dianions and has coordination number of eight. Inasmuch as the most common oxidation state for other 


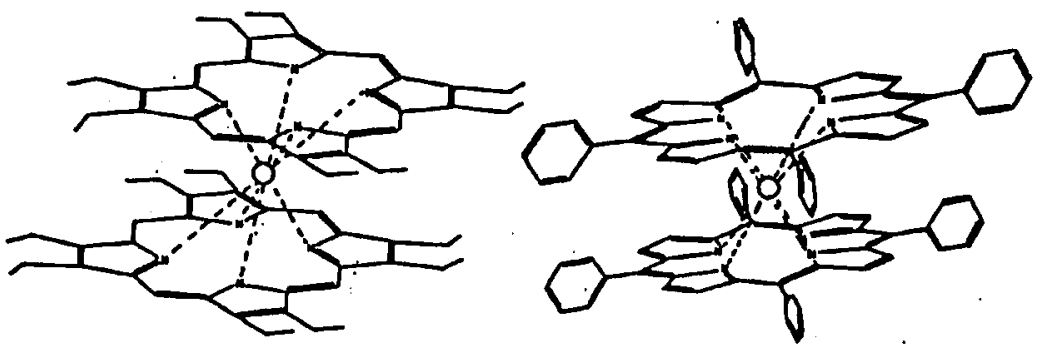

Fig. 1. Molecular structure of $\operatorname{Ln}(\mathrm{OEP})_{2}$ and $\operatorname{Ln}(\mathrm{TPP})_{2}$ complexes.

lanthanoids is $3+$, Buchler and Weiss [10-12, 14] have proposed that $3+$ ion is encompassed by one normal dianion, and second radical $\pi$ cation similar to bis(phthalocyanine)-lanthanoid(III) sandwiches $[22,23]$. Following the nomenclature originally used for the phthalocyanines [24], in which the dianion is written as $P(-2)$ and the cation radical as $P(-1)$, the formula of sandwich porphyrins can be written as $\mathrm{Ce}(\mathrm{IV})[\mathrm{P}(-2)]_{2}$ and $\operatorname{Ln}(\mathrm{III})[\mathrm{P}(-2) \mathrm{P}(-1)]$.

Much interest has been focused on the redox reaction of lanthanoid bisporphyrin complex. Radical $\pi$ cations $[\mathrm{Ce}(\mathrm{IV}) \mathrm{P}(-2) \mathrm{P}(-1)]^{+}$and $[\mathrm{Ln}(\mathrm{III})$ $P(-1)(-1)]^{+}$were formed in electrochemical and chemical ways $[9,14,16,18,25]$. Reduced Ce(IV) sandwich porphyrin had initially been observed by cyclic voltamperometry and has been isolated as the tetrabutylammonium salts [26].

We report here the results of our spectral studies on the photooxidation of bis(octaethylporphyrinato)cerium(IV) in toluene solution in the presence of $\mathrm{CCl}_{4}$ as an electron acceptor. The reaction course was followed using UV-visible and magnetic circular dichroism spectroscopy (MCD). We present also results of the photoreduction of $\mathrm{Ce}$ (IV) octaethyl- and tetraphenyl sandwich complexes in the presence of an electron donor. Steady-state photolysis of the complexes in triethylamine or toluene-triethylamine solutions were monitored by absorption spectroscopy and electron spin resonance.

\section{Experimental}

\subsection{Synthesis}

Cerium(IV) bis(octaethylporphyrinato) and bis(tetraphenyl-porphyrinato) were prepared by prolonged heating $(24 \mathrm{~h}$ ) at reflux of mixtures of cerium(III) acetylacetonate liydrate and $\mathrm{H}_{2} \mathrm{OEP}$ or $\mathrm{II}_{2} \mathrm{TPP}$, respectively in 1,2,4-trichlorobenzene under argon atmosphere, according to the procedure described originally by Buchler and co-workers $[10,14,17]$.

\subsection{Measurements}

Absorption spectra were taken with a AVIV 17DS (based on the Carry 17 monochromator) or Perkin Elmer Lambda 5 spectrophotometer, using $1 \mathrm{~cm}$ quartz cells to record in the $300-900 \mathrm{~nm}$ region at temperature of $21 \pm 1^{\circ} \mathrm{C}$. The MCD spectra were obtained either in 2 or $10 \mathrm{~mm}$ cells using a JASCO J5000 spectrometer and field of $5.5 \mathrm{~T}$ from an Oxford Instruments SM2 superconducting magnet. 
The ESR spectra were run on Bruker ER-420 and ESP-300 spectrometers. Measurements details can be found in previous papers [25,27].

\subsection{Method}

Steady-state photolysis of the argon-purged solutions was carried out at room temperature up to the moment when decomposition of the compound could first be observed by the decrease in all the bands without any change in their relative intensities. The electron acceptor $\left(\mathrm{CCl}_{4}\right)$ or donor $\left(\mathrm{Et}_{3} \mathrm{~N}\right)$ was added to the solution immediately before the commencement of photolysis. A $250 \mathrm{~W}$ halogen projector lamp was used for the sample irradiation. The light was filtered through a Cornig filter, to remove UV $(<400 \mathrm{~nm})$ radiation.

\section{Results and conclusions}

The changes in the absorption spectrum during photolysis of a $6.8 \times 10^{-6} \mathrm{~mol} \mathrm{dm}^{-3} \mathrm{Ce}(\mathrm{TPP})_{2}$ solution in toluene containing $0.3 \mathrm{~mol} \mathrm{dm}^{-3}$ triethylamine is shown in Fig. 2. Two sharp isosbestic points are present at 400 and $550 \mathrm{~nm}$. The $B$ band of the starting solution at $395 \mathrm{~nm}$ shifts to $410.5 \mathrm{~nm}$, and the $Q$ band shifts as well. The band 486 fades and new band at $610 \mathrm{~nm}$ appears. After $7 \mathrm{~min}$ of photolysis, a black solid was precipitated. To check whether the photoreduction of Ce(TPP) $)_{2}$ is reversible, $5 \%(\mathrm{v} / \mathrm{v})$ of chloroform was added

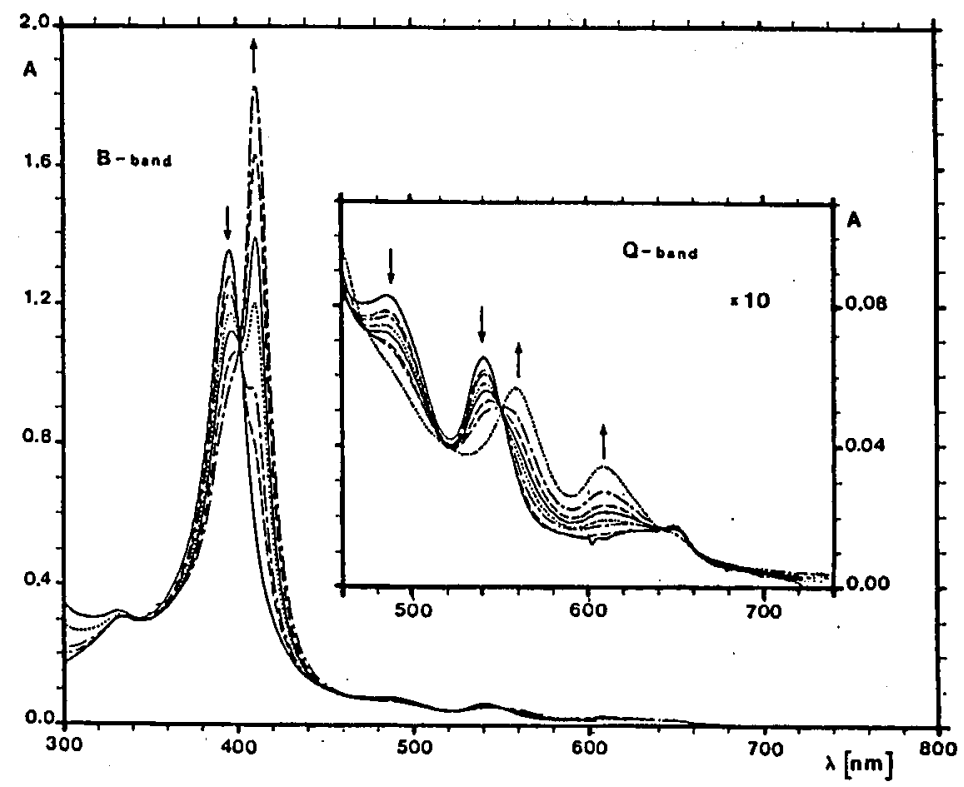

Fig. 2. Evolution of the absorption spectra of a $\mathrm{Ce}(\operatorname{IV})[\operatorname{TPP}(-2)]_{2}$ $\left(6.8 \times 10^{-6} \mathrm{~mol} \mathrm{dm}^{-3}\right)$ solution in toluene containing $0.3 \mathrm{~mol} \mathrm{dm} \mathrm{m}^{-3}$ triethylamine, upon plotoreduction. Spectra are shown for $0,0.5,1,2,3,5$ and $7 \mathrm{~min}$ of irradiation. 
to the final product of photoreduction, at the end of precipitation. After the precipitate had dissolved, the mixture was irradiated again. The photoreduction is fully reversible, two isosbestic points can be observed exactly at the same wavelengths as previously observed for the reduction process. The photoreduction of $\mathrm{Ce}(\mathrm{OEP})_{2}$ does not run so smoothly as that of the tetraphenyl sandwich. Reduction occurred when $\mathrm{Ce}(\mathrm{OEP})_{2}$ was dissolved in pure triethylamine, and flocky red-brown precipitate appeared before reaction was complete. The back oxidation is almost instantaneous.

The change in the Ce(OEP $)_{2}$ absorption and MCD spectra during photooxidation is shown in Fig. 3. The first step of oxidation involves the formation of the $\pi$ cation Ce[OEP(-1)OEP(-2)]Cl. The $B$ band of starting solution at $379 \mathrm{~nm}$ shifts to $366 \mathrm{~nm}$ and the $Q$ band changes from 574 to a series of overlapping bands. The MCD $A$ term at $574 \mathrm{~nm}$ is essentially quenched. After prolonged irradiation a new, and previously unreported, spectrum is observed. The significant red shift of the Soret band to $431 \mathrm{~nm}$, suggests that major structural changes took place. Despite the unusual spectral energies, the MCD spectra are clearly the signature of monomeric species (there is no band between 300 and $350 \mathrm{~nm}$, and the $Q$ band is quite well resolved).

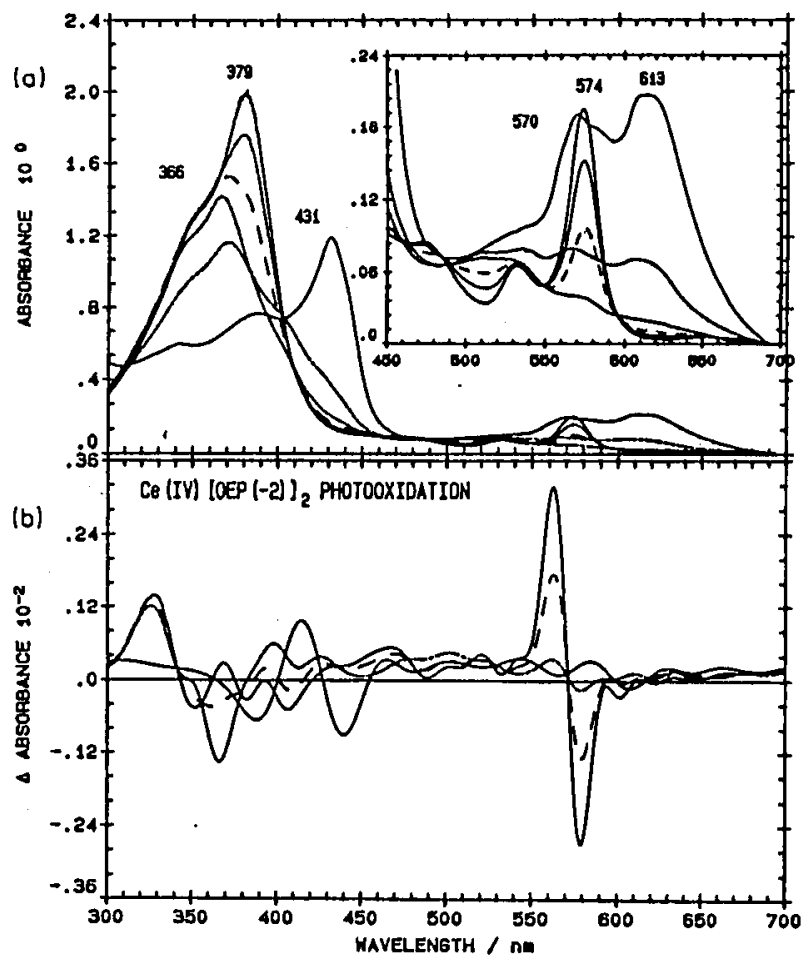

Fig. 3. Absorption (a) and MCD (b) spectra recorded during the photooxidation of $\mathrm{Ce}(\mathrm{IV})[\mathrm{OEP}(-2)]_{2}$ in toluene $+5 \% \mathrm{v} / \mathrm{v} \mathrm{CCl}_{4}$. Spectra are shown for $0,2,4,8,10$ and 20 min of irradiation. 
The Lantianide bisporphyrin Sandwich Complexes Redox Reactions

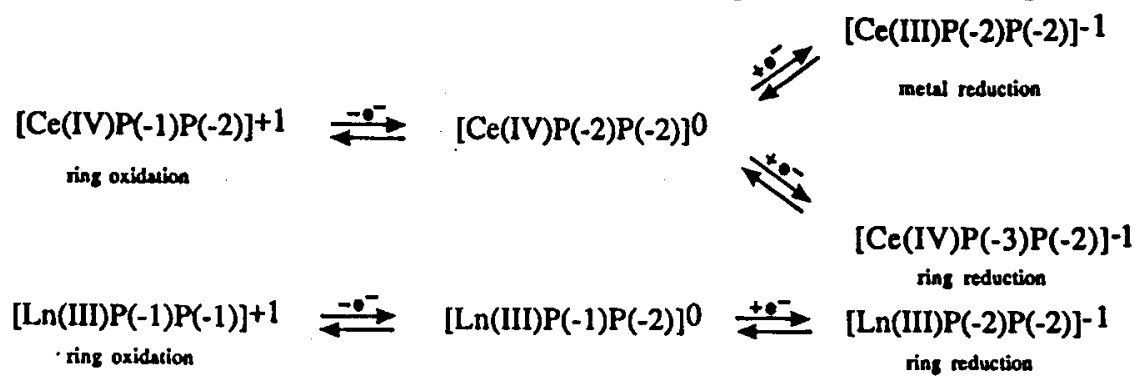

Scheme shows possible one-electron transfer reactions of the lanthanoid sandwich porphyrins. The electronic absorption spectral distribution and the intensity of bands due to the metal and ring-oxidized or -reduced porphyrins arise from the combination of $\pi-\pi^{*}$ and metal-to-ligand or ligand-to-metal charge transfer inside $18 \pi$-electron ring $[28,29]$. The electronic configurations of mono- and bis-porphyrins and theirs $\pi$ cations are shown in Fig. 4 . For the metallooctaethyloporphyrin complex as for example $\mathrm{ZnOEP}(-2)$, the electronic configuration locates the $a_{24}$ orbital accidentally degenerated with the $a_{1 u}$ orbital. Significant interaction between the lowest two excited states $B$ and $Q$ results in transition to the $B$ band being allowed and to the $Q$ band being formally forbidden, the 10:1 ratio in molar absorbances between the $B$ and $Q$ bands reflects this. Both states result in MCD $A$ terms. For the Ce[OEP $(-2)]_{2}$ exciton coupling between

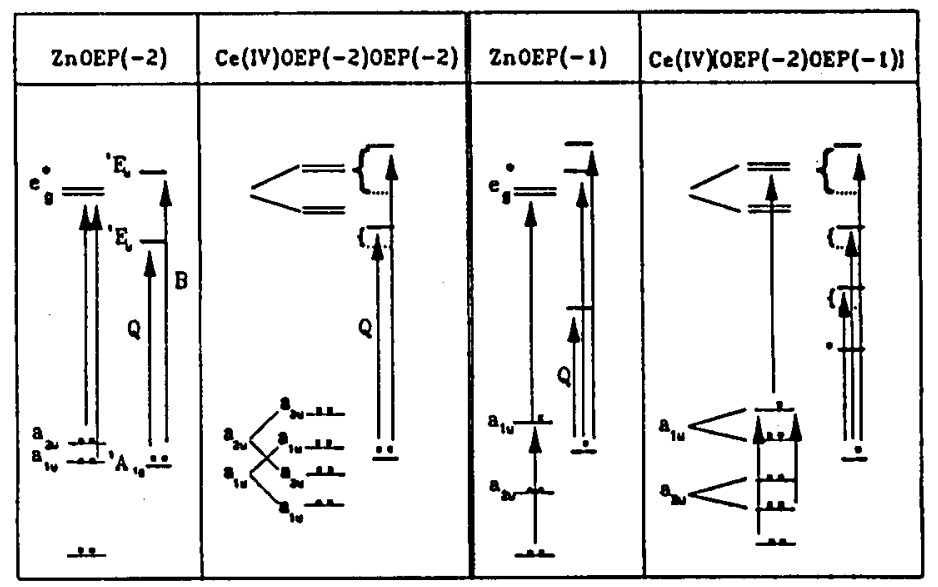

Fig. 4. Electronic configurations in neutral and oxidized monoporphyrin and sandwich bisporphyrin complexes. 
orbitals on each ring results in splitting. Transition to the upper state of each pair is allowed, while transition to the lower state is forbidden. Ring oxidation to the complex $\mathrm{ZnOEP}(-1)$ results in ground state configuration of $\left\{a_{1 \mathrm{u}}^{1} a_{2 \mathrm{u}}^{2}\right\}$ for most octaethylporphyrin metal complexes. For the Ce[OEP $(-1) \operatorname{OEP}(-2)]$ the top filled orbitals will pair up as shown in Fig. 4 . New transition into the $a_{1 \mathrm{u}}$ orbital arises from the effect of the split ground state and hole in the ground orbital, and this new transition adds additional bands to the sandwich $\pi$ cation spectrum in the near-IR region.

If the symmetry of porphyrin complex does not change (all the sandwiches considered here have symmetry $\left.D_{4 d}\right)[19,30]$ the spectra should be analogous for the compounds with the same $\pi$-electron distribution on the porphyrin rings. The spectrum of the $\pi$ cation radical [Ce(IV) $\mathrm{P}(-1)(-2)]^{+}$is essentially the same as that of the neutral trivalent lanthanoid complexes $\operatorname{Ln}(\mathrm{III})(-1) \mathrm{P}(-2)[14,18,19$, $25,31]$. The same is observed when one compares the spectrum of the $\mathrm{Ce}$ (IV)[TPP(-2)] $]_{2}$ photoreduction product with that of the product of $\operatorname{Ln}(\mathrm{III})[\mathrm{TPP}(-1) \mathrm{TPP}(-2)]$ electroreduction in the presence of tetrabutylammonium bromide [26]. These spectra are identical and we can assume that as a result of $\mathrm{Ce}(\mathrm{TPP})_{2}$ sandwich photoreduction, $[\mathrm{Ce}(\mathrm{III}) \mathrm{TPP}(-2) \mathrm{TPP}(-2)]^{-}$is formed. The absence of intense band in the region $600-800 \mathrm{~nm}$, characteristic of the radical $\pi$ anions, excludes the formation of the Ce(IV) $\pi$ anion radical (see Scheme). Formation of the $\pi$ anion radical was also not supported by ESR measurement.

The photoreduction of the Ce(IV)(OEP) $)_{2}$ sandwich is different. The final spectrum is not that of [Ce(III)OEP(-2)OEP $(-2)]^{-}$, but is essentially the same as spectra of neutral trivalent lanthanoid complexes [ $\operatorname{Ln}(\mathrm{III}) \operatorname{OEP}(-1) \operatorname{OEP}(-2)]$ (Ref. [14]). The photoreduction of the octaethyl complex is probably almost immediately followed by one-electron oxidation. In the latter process, contrary to the tetraphenyl complex oxidation, not a $\mathrm{Ce}(\mathrm{III})$, but the OEP ring is oxidized to form neutral sandwich [Ce(III)OEP(-1)OEP(-2)]. The formation of the neutral complex is confirmed by the presence of near-IR band about $1400 \mathrm{~nm}$. The ESR spectra support our conclusions, however the signal of Ce(III) was not found. This is probably due to the low concentration of the compounds, although for the ESR study saturated solutions were used. For the photoreduction product of $\mathrm{Ce}(\mathrm{OEP})_{2}$, a signal typical of organic radical is observed, similar to those of neutral Y(III) and $\mathrm{Eu}(\mathrm{III})$ octaethylporphyrinato complexes $[8,12]$. This confirms our conclusion that photoreduction leads to the formation of a neutral [Ce(III)OEP(-1)OEP $(-2)$ ] complex. For the photoreduction of the $\mathrm{Ce}(\mathrm{TPP})_{2}$ complex, only a strong signal from the $\mathrm{Et}_{3} \mathrm{~N}^{+\cdot}$ radical was observed. This radical can also play the role of counter ion in the [Ce(III)TPP(-2)TPP(-2)]- complex.

\section{R.eferences}

[1] E. Knobbier, Struct. Bond. 22, 1 (1975).

[2] R.J.P. Williams, Struct. Bond. 50, 79 (1982).

[3] W. DeW. Horrocks, R.F. Venteicher, C.A. Spilburg, B.L Vallee, Biochem. Biophys. Res. Commun. 64, 317 (1975).

[4] J.C.G. Buenzli, G.R. Choppin, Lanthanide Probes in Life, Chemical and Earth Sciences, Elsevier, Amsterdam 1989. 
[5] C.P. Wong, R.F. Venteicher, W. DeW. Horrocks, J. Am. Chem. Soc. 96, 7149 (1975).

[6] W. DeW. Horrocks, C.P. Wong, J. Am. Chem. Soc. 98, 7157 (1976).

[7] J.W. Buchler, H.H. Schneehage, Z. Nat.forsch. B 28, 433 (1975).

[8] J.W. Buchler, M. Knoff, in: Optical Properties and Structure of Tetrapyrroles, Eds. G. Blauer, H. Sound, Walter de Gruyer \&Co., Berlin 1985, p. 91.

[9] J.W. Buchler, K. Elsasser, M. Kihn-Botulinski, B. Scharbert, Angew. Chem. Int. Ed. Engl. 25, 286 (1986).

[10] J.W. Buchler, A. De Cian, J. Fischer, M. Kihn-Botulinski, H. Paulus, R. Weiss, J. Am. Chem. Soc. 108, 3652 (1986).

[11] J.W. Buchler, A. De Cian, J. Fischer, M. Kihn-Botulinski, R. Weiss, Inorg. Chem. 27, 339 (1988).

[12] J.W. Buchler, J. Huttermann, J. Lofler, Bull. Chem. Soc. Jpn. 61, 71 (1988).

[13] J.W. Buchler, M. Kihn-Botulinski, B. Scharbert, Z. Nat.forsch. B 43, 1371 (1988).

[14] J.W. Buchler, B. Scharbert, J. Am. Chem. Soc. 110, 4272 (1988).

[15] J.W. Buchler, H.-G. Kapellmann, M. Knoff, K.-L. Lay, S. Pfeifer, Z. Nat.forsch. B 38, 1339 (1983).

[16] R.J. Donohue, J.K. Duchowski, D.F. Bocian, J. Am. Chem. Soc. 110, 6119 (1988).

[17] J.W. Buchler, J. Loffer, Z. Nat.forsch. B 45, 531 (1990).

[18] J.W. Buchler, A. De Cian, J. Fischer, P. Hammerschmidt, J. Loffer, B. Scharbert, R. Weiss, Chem. Ber. 122, 2219 (1989).

[19] J.K. Duchowski, D.F. Bocian, J. Am. Chem. Soc. 112, 3312 (1990).

[20] M. Lachkar, A. De Cian, J. Fischer, R. Weiss, New J. Chem. 12, 729 (1988).

[21] D. Chabach, M. Lachkar, A. De Cian, R. Weiss, New J. Chem. 16, 431 (1992).

[22] J.C. Marchon, A. Chang, Inorg. Chim. Acta 53, L241 (1981).

[23] A. De Cian, M. Moussavi, J. Fischer, R. Weiss, Inorg. Chem. 24, 3162 (1985).

[24] Phlhalocyanines. Principles and Properties, Eds. A.B.P. Lever, C.C. Leznoff, VCH, New York 1989.

[25] S. Radzki, J. Mack, M.J. Stillman, New J. Chem. 16, 583 (1992).

[26] J.W. Buchler, P. Hammerschmidt, K. Kaufeld, J. Loffer, Chem. Ber. 124, 2151 (1991).

[27] S. Radzki, C. Giannotti, J. Chem. Soc. Dalton Trans., 675 (1993).

[28] M. Gouterman, in: The Porphyrins, Ed. D. Dolphin, Vol. 3, Part A, Academic Press, New York 1978, p. 1.

[29] Z. Gasyna, M.J. Stillman, Inorg. Chem. 29, 5101 (1990).

[30] O. Bisel, J.W. Buchler, P. Hammerschmitt, J. Rodrigez, O. Holten, Chem. Phys. Lett. 182, 415 (1991).

[31] J.-H. Perng, J.K. Duchowski, D.F. Bocian, J. Phys. Chem. 94, 6684 (1990). 